\title{
Pressupostos Processuais e Condições da Ação.
}

\author{
Luís Eulalio de Bueno Vidigal, \\ Catedrático de Direito Processual Civil na \\ Faculdade de Direito da Universidade de \\ São Paulo.
}

1 Desde a publicação do livro de OsKar BüLow, que alguns consideram o primeiro passo na senda do direito processual moderno ${ }^{1}$, vêm quase todos os autores adotando a denominação "pressupostos processuais" a certos requisitos que se devem verificar antes da entrega da prestação jurisdicional.

Assim, entre os brasileiros, Moacyr Amaral Santos:

"Pressupostos processuais são os requisitos necessários a se conseguir uma decisão qualquer, favorável ou desfavorável à pretensão do autor, tais como a existência de um órgão do Estado, regularmente investido de jurisdição; a competência dêsse órgão em relação à natureza da causa; a capacidade de ser parte e a capacidade processual" 2 .

E mais tarde:

"Conceituamos pressupostos processuais como sendo os requisitos necessários à existência e validade da relação processual" 3 .

Pouco antes, no mesmo sentido, Alfredo Buzaid:

"Essa importante doutrina, estudando o vasto e complexo material de conhecimento que se apresenta ao juiz

1. Die Lehre von den Prozesseinreden und die Prozessvoraussetzungen.

2. As condições da ação no despacho saneador, São Paulo, 1946, p. 14.

3. Primeiras linhas de Direito Processual Civil, Max Limonad, São Paulo, 1962, p. 373. 
para que êle possa conhecer do pedido das partes e dar razão a quem a tem, separou os pressupostos em duas grandes classes, reservando para uma o nome de pressupostos processuais (Prozessvoraussetzungen) e para outra, a denominação de pressupostos da ação (Klagvoraussetzungen). Os primeiros compreendem as condições para a obtenção de um pronunciamento qualquer, favorável ou desfavorável, sôbre a demanda. Negando-se a existência dos pressupostos processuais, não se nega a existência da ação. Esta não é decidida. Os segundos são condições necessárias a que o juiz declare existente e atui a vontade concreta da lei invocada pelo autor, vale dizer, as condições necessárias para obter um pronunciamento favorável. $O$ valor desta contraposição consiste em considerar os primeiros, pressupostos do exame do mérito, ao passo que as condições da ação são os requisitos do mérito pròpriamente dito". 4

Galeno LACERDA, em seguida, adotando o instituto, discrepa ligeiramente. Afirma que os pressupostos processuais não são requisitos da existência e sim de legitimidade do processo. ${ }^{5}$

2. Nota-se, do confronto do pensamento dêsses ilustres processualistas brasileiros com o dos primeiros autores alemães que primeiro trataram do assunto, nítida evolução.

BüLow dizia que os pressupostos processuais são os requisitos para a admissibilidade (die Erfordenisse für die Zulässigkeit), as condições prévias para a formação definitiva de tôda a relação processual (die Vorbedingungen für das Zustandekommen des ganzen Prozessverhältnisses), a condição de existência da relação processual, os requisitos para a válida formação definitiva da relação processual. 6

4. Do Agravo de Petição no Sistema do Código de Processo Civil, 2. ${ }^{a}$ edição, Saraiva, São Paulo, 1956, p. 84.

5. Despacho Saneador, Livraria Sulina, Pôrto Alegre, 1953, p. 68.

6. apud AlFredo BUzAID, in ob. cit., p. 85. 
KoHLER, no mesmo sentido, afirmava não nascer qualquer processo e não se formar qualquer relação processual se faltasse um pressuposto processual. ${ }^{7}$

Finalmente, STtEIN sustentou que, faltando um pressuposto processual, sòmente há uma existência de fato do processo, sem, contudo, existência jurídica. ${ }^{8}$

3. Estes três autores alemães entendem, em resumo, que a relação jurídica processual não chega a constituir-se se falta um pressuposto processual.

Os três autores brasileiros citados, diversamente, opinam no sentido de que, sem os pressupostos processuais, não pode haver decisão de mérito ou processo legítimo.

Já se notava em Chrovenda o germe dessa evolução do pensamento original dos alemães para o contemporâneo dos estudiosos brasileiros: "faltando uma destas condições" - os pressupostos processuais — "não nasce a obrigação do juiz, de prover sôbre o mérito".

"Todavia" - prossegue Chiovenda — "ainda nesse caso o juiz tem uma obrigação: e é a de declarar porque não pode prover sôbre o mérito. Há, portanto, também nesse caso uma relação jurídica. Esta relação processual mais restrita não reclama como pressuposto senão a existência de um órgão jurisdicional; sem êste não é sequer concebível uma sentença que declare não prover a respeito do mérito dos pedidos". 9

Cabe, porém, a um ilustre mestre brasileiro, José Joaquim Calmon de Passos, da Faculdade de Direito da Universidade da Bahia, o mérito de haver formulado, em monografia assinada, a mais correta apresentação do problema. Três são, em sua opinião, que é também a nossa, os pressupostos processuais: órgão jurisdicional, entidade

\footnotetext{
7. apud ALFREDO BUZAID, in loc. cit.

8. apud ALFRedo BuZaI, in loc. cit.

9. Istituzioni, $2 .^{\mathrm{a}}$ ed., $10^{\circ}$ v., p. 54.
} 
provida de capacidade processual e petição desta última dirigida ao primeiro. ${ }^{10}$

4. Ilustremos, com um exemplo, nossa opinião. Figuremos petição apresentada por estrangeiro (sem bens e sem caução) a juiz do cível absolutamente incompetente e impedido por suspeita objetiva de parcialidade. Faltam, nesse caso, pelo menos três dos pressupostos tradicionalmente exigidos pela doutrina: caução às custas, compelência objetiva e capacidade subjetiva do juiz.

Indeferida a petição inicial por inépcia, caberá ao autor o recurso de agravo de petição. Negado provimento ao agravo pelo tribunal de apelação, o agravante apresentará recurso extraordinário que, indeferido liminarmente pelo Presidente do Tribunal, subirá, como agravo de instrumento ao Supremo Tribunal Federal, onde se lhe negará provimento.

Até chegar a êsse resultado, o autor pôde exigir do juiz de primeira instância o despacho inicial de indeferimento, o despacho na petição de agravo, o despacho de sustentação do inicial e todos os despachos de expediente necessários à subida do recurso. Do Tribunal de Apelação e do Supremo Tribunal Federal as decisões colegiadas confirmatórias do despacho inicial. Do pessoal do juízo, em primeira instância: a distribuição de causa, o registro, a expedição e o cumprimento do mandado, a autuação, a contagem de custas, a remessa à instância superior, etc. $\mathrm{Na}$ instância superior e no Supremo Tribunal Federal: recebimento, autuação, expedição de guias de preparo, recebimento de preparo, audiência de Ministério Público, passagens de autos, publicações no Diário Oficial, etc.

Se, como preconizou Chrovenda, com a adesão de grandes contingentes doutrinários, aceitarmos a idéia da relação jurídica processual, como poderemos negar a êsse

10. A Ação no Direito Processual Civil Brasileiro, Oficinas Gráficas da Imprensa Oficial da Bahia, 1960, ps. 48 e 49. 
conjunto de direitos, deveres, ônus e obrigações, a inclusão nessa categoria?

É bem certo que Chiovenda, no tópico citado $\left(n .^{\circ} 3\right.$ supra), reconheceu, nesse caso, a existência de uma relação processual mais restrita que não reclama como pressuposto senão a existência de um órgão jurisdicional. Feita, porém, essa concessão, sòmente êstes últimos requisitos, não os demais, deverão ser considerados como pressupostos processuais.

5. A impropriedade da expressão "pressupostos processuais" talvez tenha contribuído para essas dúvidas e vacilações.

A expressão empregada originàriamente por OsKar BüLow foi "Prozessuale Voraussetzungen". "Voraussetzungen" quer dizer suposição, pressuposição, pressuposto, hipótese. Nenhum dêsses significados corresponde ao sentido em que se emprega aquela expressão.

Sejam os pressupostos os requisitos necessários para a constituição da relação processual, sejam os necessários para uma sentença qualquer, ou finalmente, os necessários para uma sentença de mérito, a denominação sempre permanece inadequada.

Porque fugir à terminologia tradicional da teoria geral do direito brasileiro?

Há um ato necessário para a constituição da relação jurídica processual. Que ato é êsse? É a propositura da ação. Em que consiste a propositura da ação? Em uma declaração de vontade feita por uma entidade a outra.

Quais são os elementos essenciais dessa declaração de vontade?

a) capacidade processual de quem a emite;

b) poder jurisdicional em quem a recebe.

É inútil acrescentar outros requisitos a êsse rol. Esses bastam para o nascimento e o desenvolvimento da relação processual. Não desejamos fazer inovações terminológicas. 
Por isso, deixamos de propôr, para êsses chamados pressupostos, sua correta denominação, que seria "condições da atividade jurisdicional".

6. ecioso, para os objetivos dêste estudo, porque não lhe alteraria as conclusões, o debate (que teria pertinência) a respeito do próprio conceito de relação jurídica processual. As conclusões a que chegamos, em nosso estudo a respeito da natureza da ação judicial, muito nos aproximariam daqueles que negam a existência de uma relação jurídica processual pròpriamente dita. Se êste e aquêle trabalho, ao invés de estudos autônomos, fôssem capítulos de um ambicioso sistema de direito processual, seríamos aqui forçados a certas adaptações. Como estudos isolados que são, ficaremos, em cada um, em tudo quanto não se relacione com seus objetivos imediatos, com a técnica e a terminologia tradicionais.

7 Vimos, pois, quais são os requisitos mínimos para a provocação da atividade jurisdicional. Prossigamos em nosso estudo em busca dos requisitos que devem ser satisfeitos para que a atividade jurisdicional atinja seu escôpo: atuação da vontade concreta da lei para composição dos conflitos de interêsses.

A doutrina predominante acrescenta aos requisitos mínimos que apontamos os necessários para o válido desenvolvimento da relação processual (CHюvenda, Istituzioni, pág. 54), para a legitimidade do processo (Galeno Lacerda, ob. cit., pág. 68), para o desenvolvimento e validade do processo (Alfredo Buzaid, ob. cit., pág. 86).

Preferimos a fórmula de BuzaID. A relação processual não é válida ou inválida, como pareceu a Chiovenda; nem legítima ou ilegítima, como propôs Galeno LAcerda. A relação processual é a resultante dos atos e fatos constitutivos e das circunstâncias modificadoras. São os atos 
do processo, a atividade processual, o processo, enfim, é que devem ser válidos, isto é, adequados aos seus objetivos.

A segunda ordem dos requisitos para que a jurisdição atinja seu escôpo é, pois: validade dos atos do processo. Nela se incluem todos aqueles requisitos que a doutrina mais autorizada (Chrovenda, Moacyr Amaral Santos, GaLENo LACERDA) considera, além dos dois que indicamos, como pressupostos processuais.

Tais são:

I - referentes ao juiz:

a) que o juiz tenha competência originária ou adquirida;

b) que o juiz seja imparcial.

II - referentes às partes:

a) que tenham capacidade processual;

b) que tenham capacidade de postular em juízo.

III - referentes aos atos do processo:

a) inexistência de atos impeditivos;

b) subordinação do procedimento às normas legais. ${ }^{11}$

8. Os demais requisitos para que a atividade jurisdicional atinja seu escôpo são os que a doutrina costuma chamar de condições da ação. CHIovenda, porém, para quem a ação é o direito à sentença favorável ao autor, afirma que as condições da ação são as mesmas condições do provimento favorável ao autor.

Nós, que concebemos a ação como o poder de atuar a vontade concreta da lei, por via jurisdicional, para a

11. Moacyr Amaral Santos, Primeiras Linhas, p. 360; Galeno LACERDA, Despacho Saneador, p. 61. 
composição dos conflitos de interêsses, teremos de distinguir entre condições de admissibilidade da ação (requisitos para um pronunciamento judicial de mérito qualquer, favorável ou contrário ao autor) e condições de procedência da ação (requisitos para um pronunciamento judicial favorável ao autor).

Requisitos de admissibilidade são, segundo a mais autorizada doutrina, aqueles sem os quais se verifica a chamada carência de ação, isto é, o interêsse processual de agir, a possibilidade jurídica e a legitimação para agir. ${ }^{12}$

Admissibilidade é substantivo derivado do adjetivo admissível que, por sua vez, é derivado do verbo admitir e o sufixo "ivel" Este sufixo exprime a qualidade de entidades que possam sofrer, ou estejam em condições de receber, a ação verbal. Admissível é o que está em condições de ser admitido. Admissibilidade é a situação ou a qualidade própria para ser admitido.

A ocorrência dos três requisitos - interêsse processual de agir, possibilidade jurídica e legitimação para agir - verificável em tese, propicia a possibilidade do julgamento da procedência da ação.

Foi muito feliz a inovação do Código de Processo Civil Brasileiro que, a nosso ver, permitiu francamente o julgamento do mérito no despacho saneador. É a solução imposta pelo princípio da economia processual e decorrência lógica do velho instituto da carência de ação que, a não ser assim, seria completamente irrelevante ${ }^{13}$.

12. EnRICo TUlio Liebman, O Despacho Saneador e o Julgamento do Mérito, Revista Forense, vol. 104, p. 223.

LuIZ MACHADo Guimarães, no verbete "Carência de ação" do Repertório Enciclopédico do Direito Brasileiro, v. VI, ano 1950.

13. Nesse sentido, Moacyr Amaral Santos, As Condições da Ação no Despacho Saneador, ps. 63, 78 e 96; Galeno LACERDA, Despacho Saneador, p. 88. 
Não pretendemos abundar em considerações, que foram ampla e brilhantemente expostas por MoacYr Amaral SANTos em sua excelente monografia sôbre As Condições da Ação no Despacho Saneador. Permita-se-nos, todavia, aduzir alguns exemplos que ilustram sua tese.

Quanto ao interêsse processual de agir. O juiz, por exemplo, declara o autor carecedor de ação de cobrança porque omitiu as providências necessárias à satisfação de seu crédito querable e não portable. É julgamento de mérito porque o fato que leva à carência de ação é um dos que constituem a causa petendi do autor. Se outro pedido se seguir, em que o autor alegue e prove ter dado essas providências, teremos, com a modificação da causa petendi, nova ação, que poderá vir a ser julgada procedente.

Quanto à possibilidade juridica. O juiz que, com base nela, declara o autor carecedor de ação, nega que dos fatos alegados e juridicamente qualificados possa decorrer o provimento pedido pelo autor. Se, em pedido subseqüente, o autor requerer provimento diverso, temos nova ação que, com objeto mudado, pode vir a ser julgada procedente.

Quanto à legitimação para agir. Mais claramente do que nos dois exemplos precedentes, é evidente que a modificação da parte pode levar a decisão judicial diversa.

As condições da ação são, pois, os requisitos que, negados em tese, levam à carência de ação. Afirmados em tese, levam à admissibilidade da procedência do pedido e, portanto, permitem o prosseguimento do processo.

9. Finalmente, as condições de procedência da ação. Ao verificar as condições de admissibilidade, já o juiz formulou seu julgamento sôbre a existência da norma jurídica invocada pelo autor e sôbre a qualificação jurídica dos fatos alegados. Para declarar procedente a ação, terá apenas de verificar: 
$\left.1^{\circ}\right)$ se tais fatos ocorreram;

2. ) se não ocorreram circunstâncias que lhes alterem a qualificação jurídica;

$\left.3^{\circ}\right)$ se os fatos alegados pelo réu, devidamente qualificados e provados, não elidem a pretensão do autor. 